Retraction

Open Access

G. Bhanuprakash Reddy, P. Yadagiri Reddy, Avadhesha Surolia

\title{
Retraction of: Alzheimer's and Danish dementia peptides induce cataract and perturb retinal architecture in rats
}

https://doi.org/10.1515/bmc-2021-0012

received January 22, 2017; accepted March 23, 2018.

Retraction of: Reddy, G. Bhanuprakash, Reddy, P. Yadagiri and Surolia, Avadhesha. "Alzheimer's and Danish dementia peptides induce cataract and perturb retinal architecture in rats" Biomolecular Concepts, vol. 8, no. 1, 2017, pp. $45-84$. https://doi.org/10.1515/bmc-2016-0025

The authors and the publisher would like to inform that the article "Alzheimer's and Danish dementia peptides induce cataract and perturb retinal architecture in rats" (https://doi.org/10.1515/bmc-2016-0025) has been retracted due to concerns about the scientific creditability of figure 3 and figure 5 .

G. Bhanuprakash Reddy, Avadhesha Surolia, Biochemistry Division, National Institute of Nutrition, Hyderabad 500007, Telangana, India P. Yadagiri Reddy, Molecular Biophysics Unit, Indian Institute of Science, Bengaluru 560012, Karnataka, India 